\title{
Role of Fetal Thigh Circumference in Estimation of Birth Weight by Ultrasound
}

\author{
${ }^{1}$ Krishna Dahiya, ${ }^{2}$ Sonal Grover, ${ }^{3}$ Jyotsna Sen, ${ }^{1}$ Nirmala Duhan, ${ }^{1}$ Smiti Nanda \\ ${ }^{1}$ Professor, Pt BD Sharma Postgraduate Institute of Medical Sciences, Rohtak, Haryana, India \\ ${ }^{2}$ Resident, Pt BD Sharma Postgraduate Institute of Medical Sciences, Rohtak, Haryana, India \\ ${ }^{3}$ Professor, Department of Obstetrics and Gynecology and Radiodiagnosis, Pt BD Sharma Postgraduate Institute of \\ Medical Sciences, Rohtak, Haryana, India
}

Correspondence: Krishna Dahiya, Professor, Pt BD Sharma Postgraduate Institute of Medical Sciences, 74-R, Model Town Rohtak-124001, Haryana, India, Phone: 01262211888, e-mail: krishnadahiya@ rediffmail.com, drkrishnadahiya@gmail.com

\section{ABSTRACT}

Objective: To evaluate the accuracy and usefulness of predicting birth weight by measuring fetal thigh circumference by ultrasound and to compare with other conventional methods like Johnson's and Hadlock's.

Methods: In 100 pregnant women, ultrasonic measurements of mid-thigh circumference, along with BPD, FL and AC were done within 48 hours before delivery. Birth weights were estimated by Johnson's clinical method, Hadlock's and Vintzileos' method. Statistical analysis of various ultrasound birth weight formulae in different weight categories was done and compared with each other, and also with clinical method.

Results: In the present study, Vintzileos' method was found to be better than Johnson's and Hadlock's in predicting birth weight in the categories < $2500 \mathrm{gm}$, and 2500 to $3000 \mathrm{gm}$. Between 3000 and $3500 \mathrm{gm}$, it was better than Johnson's method, while the results were comparable to Hadlock's method. In the category $>3500 \mathrm{gm}$, all three methods were comparable to each other, however it could be because of the small sample size involved $(n=6)$.

Conclusions: Incorporating fetal thigh circumference measurements along with biparietal diameter, femur length and abdominal circumference, significantly improved the accuracy of birth weight estimations by ultrasound. There was a good correlation between ultrasound measurements and actual postnatal measurements of thigh circumference $\left(r^{2}=0.71\right)$.

Keywords: Fetal thigh circumference, Ultrasound, Birth weight.

\section{INTRODUCTION}

Birth weight of a baby has direct links with the gestational age at which the child is born and can be estimated during the pregnancy by using various techniques.

Tactile assessment of fetal size is the oldest technique for assessing fetal weight. Worldwide, this method is used extensively because it is both convenient and virtually costless. However, it is a subjective method associated with notable predictive errors and is not useful in malpresentations, maternal obesity, multifetal pregnancy, polyhydramnios and oligohydramnios. ${ }^{1-2}$ Several investigations have shown that the accuracy of clinical palpation for estimating fetal weight is \pm 278 to $599 \mathrm{gm}$ ( $\pm 7.5-19.8 \%$ ), and is best for estimating fetal weight in reference range 2500 to 4000 gm. $^{3,4}$

The most modern method for assessing fetal weight in utero involves the use of fetal measurements like biparietal diameter, head circumference, abdominal circumference and femur length, obtained during obstetrical ultrasonography. The advantage of this technique is that it relies on linear and/or planar measurements of in utero dimensions that are objectively definable and probably reproducible.
Vintzileos et al reported that the model incorporating 5 parameters viz. HC, BPD, AC, FL and TC gave the best results predicting the actual weight within $+/-5 \%$ in $54 \%$ of the cases, and within $+/-10 \%$ in $80.3 \%$ of the cases.

We carried out this study to see whether addition of fetal thigh circumference (Vintzileos' method) improves the accuracy in prediction of birth weight or not as compared to more commonly used Hadlock's method (based on BPD, AC and FL) and the clinical palpation method.

\section{MATERIALS AND METHODS}

The present study was conducted in the Departments of Obstetrics and Gynecology and Radiodiagnosis, and Imaging at Pt BD Sharma PGIMS, Rohtak. One hundred pregnant women, near term (37-41 weeks) with singleton pregnancies, without any high-risk factor, admitted in the Labour Ward, PGIMS, were selected for the study.

After taking informed consent from the patient, detailed history was elicited followed by general, systemic, and obstetric examination. Patient was subjected to routine investigations. 
Clinically, symphysio-fundal height was measured after ensuring an empty bladder. The station of the head was also determined, and Johnson's method was applied to predict the fetal weight. ${ }^{18}$ The patients were then subjected to ultrasonography to measure the biparietal diameter, abdominal circumference, femur length and thigh circumference within 48 hours before delivery. The ultrasonic measurements were made with machines equipped with a $3.5 \mathrm{MHz}$ convex probe. Ultrasound velocity was $1540 \mathrm{~m} / \mathrm{sec}$. Freeze frame capability was available, and on screen calibers were used for the measurements. Birth weights were estimated using Hadlock’s and Vintzileos' equations.

Patients were followed up till delivery of the baby. If delivery did not occur within 48 hours then estimations were repeated and these repeat estimations were taken into account. Within half an hour of delivery, neonates were weighed on weighing scale and thigh circumference of the neonate was measured at the middle of the thigh using measuring tape for comparison with ultrasound measurements.

\section{Measurement of Thigh Circumference}

The thigh circumference was measured according to the technique of Vintzileos et al. The long axis of the femur was first imaged, the transducer was then rotated 90 degrees to obtain a cross-sectional profile of the middle of the thigh at a position that the bone profile was as round as possible and the boundary of the thigh profile was well defined (Figs 1 and 2). All circumferences (abdomen, thigh) were determined with the formula ' $\mathrm{D} 1+\mathrm{D} 2 \times 1.57$ ' on the basis of two diameters at right angles to one another. This technique has been demonstrated to give results equivalent to those obtained with a map measurer. ${ }^{19}$

\section{Statistical Analysis}

Birth weights were then predicted by applying Hadlock's and Vintzileos' methods. Calculation of mean, mean residual, mean absolute error, mean absolute percentage error, and mean

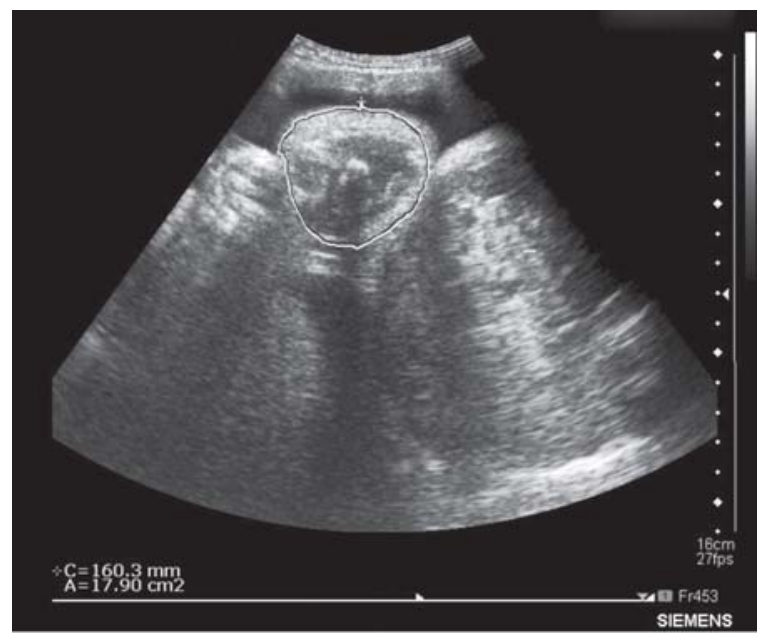

Fig. 1: Ultrasonic view showing mid-thigh circumference corresponding to 39 weeks' gestation

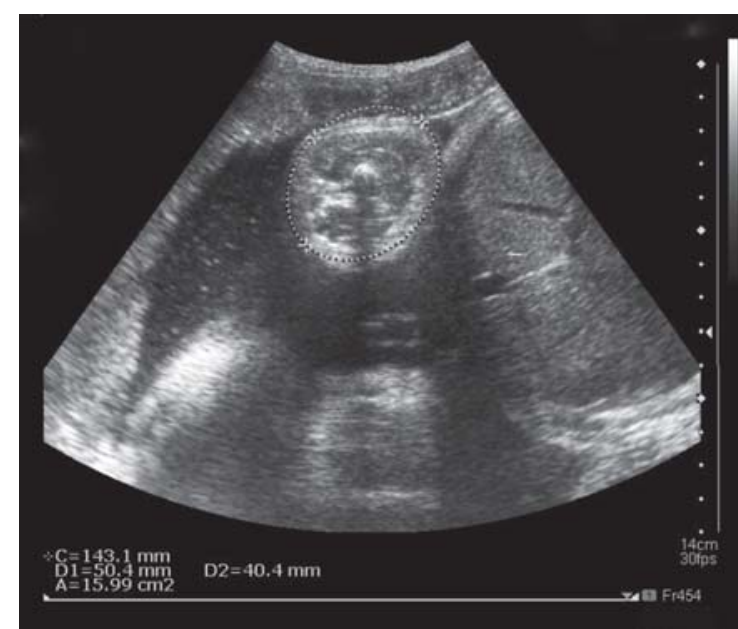

Fig. 2: Ultrasonic view showing mid thigh circumference corresponding to 38 weeks' gestation

deviation was done using Microsoft Excel 2003. Student's t-tests and chi-square tests were used to assess the significance of results. The differences were considered significant if p-value was less than 0.05 .

\section{RESULTS AND ANALYSIS}

The mean age of patients was $23.71 \pm 2.89$ years and the range was from 19 to 37 years. Maximum number of patients (52\%) were nullipara. The mean gestational age was 39.2 weeks and ranged from 37 to 41 weeks.

The mean biparietal diameter was $8.93 \pm 0.38 \mathrm{~cm}$ and ranged from 8.08 to $9.85 \mathrm{~cm}$. The abdominal circumference had a mean value of $30.33 \pm 2.16 \mathrm{~cm}$ and the range was from 25.3 to $37.2 \mathrm{~cm}$. The mean femur length was $7.06 \pm 0.33 \mathrm{~cm}$ and ranged from 6.3 to $7.9 \mathrm{~cm}$ while the mean thigh circumference was $14.1 \pm 1.54 \mathrm{~cm}$ and ranged from 11 to $18 \mathrm{~cm}$. The mean birth weight of neonates was $2863 \pm 441$ grams with a range from 2000 to $4500 \mathrm{gm}$.

Fifty two women (52\%) were from urban background while $48 \%$ were from rural background. The mean weight of infants from urban background was $2894 \pm 436$ grams, with a range from 2000 to $4100 \mathrm{gm}$. The mean weight of infants from rural background was $2829 \pm 453$ grams with a range from 2200 to 4500 gm.

Out of 100, 60 (60\%) were male babies and 40 (40\%) were female babies. The average weight of male neonates was 3081 \pm 386 grams, with a range from 2200 to $4500 \mathrm{gm}$. The average weight of female neonates was $2535 \pm 300$ grams with a range from 2000 to $3400 \mathrm{gm}$.

Fifty two (52\%) patients were nullipara, 42 (42\%) were primipara and 6 (6\%) were multipara.The average weight of infants born to nulliparous women was $2760 \pm 382$ grams with a range from 2000 to $3650 \mathrm{gm}$. The average weight of infants born to primipara women was $2989 \pm 508$ grams with a range from 2200 to $4500 \mathrm{gm}$. The average weight of infants born to multipara women was $2875 \pm 219$ grams with a range from 2500 to 3100 gm. 
Sixty six (66\%) subjects had hemoglobin less than $10 \mathrm{gm} \%$, and 34 (34\%) had hemoglobin equal to or greater than $10 \mathrm{gm} \%$. Mean birth weight of babies born to mothers with hemoglobin less than 10 gm\% was $2867 \pm 393$ grams (range 2000-4500 grams), as compared to birth weight of babies born to mothers with hemoglobin $\geq 10$ gm $\%$ which was $2801 \pm 449$ grams (range 2000-4200 grams). The coefficient of correlation between hemoglobin and actual birth weight was -0.1522 , which explains that birth weight decreases with increase in hemoglobin concentration.

\section{Comparative Analysis of Different Methods}

All the results were assessed in four categories: < 2500, 2500 to 3000,3000 to 3500, and more than $3500 \mathrm{gm}$. The sample sizes of these four categories were 26, 45, 23 and 6 respectively.

In 1st category (<2500 g, $\mathrm{n}=26)$, Hadlock's method resulted in lower mean residual and mean deviation compared to Vintzileos' method (p value-0.64). The mean absolute error and mean absolute percentage error were lower by Vintzileos' method as compared with Hadlock's method (p value-0.02457). However, both Hadlock's and Vintzileos' were better than Johnson's in predicting these values with significant p-values.

In the 2nd category (2500-3000 g, $\mathrm{n}=45$ ), Vintzileos' method produced lower mean residual and mean deviation $(p=0.65)$. The results were significant when compared with Johnson's method. Vintzileos' method also produced lower mean absolute error and mean absolute percentage error compared to Hadlock's and Johnson's ( $p=0.0280$ ).

In the 3rd category (3000-3500 g, $\mathrm{n}=23$ ), Vintzileos' method produced a lower mean residual and mean deviation as compared to Hadlock's and Johnson's. However, when compared with Hadlock's method, these results were not significant ( $p=0.48)$, but when compared with Johnson's method, these results were significant.

Vintzileos' method produced a lower mean absolute error and mean absolute percentage error than Hadlock's and Johnson's methods $(\mathrm{p}=0.033)$.

In the 4th category ( $>3500 \mathrm{~g}, \mathrm{n}=6$ ), Vintzileos' method was better than Johnson's in predicting mean residual and mean deviation. These results were comparable to Hadlock's method. The mean absolute error and mean absolute percentage error were comparable by all three methods.

Vintzileos' method was found to be better than Johnson's and Hadlock's in predicting birth weight in the categories
< 2500 gm, and 2500 to 3000 gm. Between 3000 and 3500 gm, it was better than Johnson's method, while the results were comparable to Hadlock's method. In the category > 3500 gm, all three methods were comparable to each other, however it could be because of the small sample size involved $(n=6)$. Overall, Vintzileos' method was more accurate than the other two methods in predicting birth weights within $\pm 10 \%$ of actual birth weight.

Table 1 demonstrates that the coefficient of correlation was highest with Vintzileos' method (0.9543) as compared with the other two methods. The mean of birth weight predicted by Vintzileos' method was closest to actual birth weight. Vintzileos' method also produced a lower mean residual than Hadlock's and Johnson's method. However, Vintzileos' and Hadlock's methods were comparable in this aspect ( $p=0.4317)$, and they were better than Johnson's method. The mean absolute error and mean absolute percentage error were lowest with Vintzileos' method, and significantly better than Hadlock's method ( $p=0.00064)$ and Johnson's method. Vintzileos' method also had a highest ability to predict birth weight within $10 \%$ of actual birth weight (89\%) as compared to Hadlock's method ( $\mathrm{p}<0.05)$ and Johnson's method ( $<<0.05)$.

The mean of estimated thigh circumference was $13.9 \pm$ $1.61 \mathrm{~cm}$ with a range from 11 to $18.6 \mathrm{~cm}$. The mean of actual thigh circumference was $14.1 \pm 1.54 \mathrm{~cm}$ and the range was from 11 to $18 \mathrm{~cm}$. The coefficient of correlation $\left(\mathrm{r}^{2}\right)$ of estimated and actual thigh circumference was 0.71 (Fig. 3).

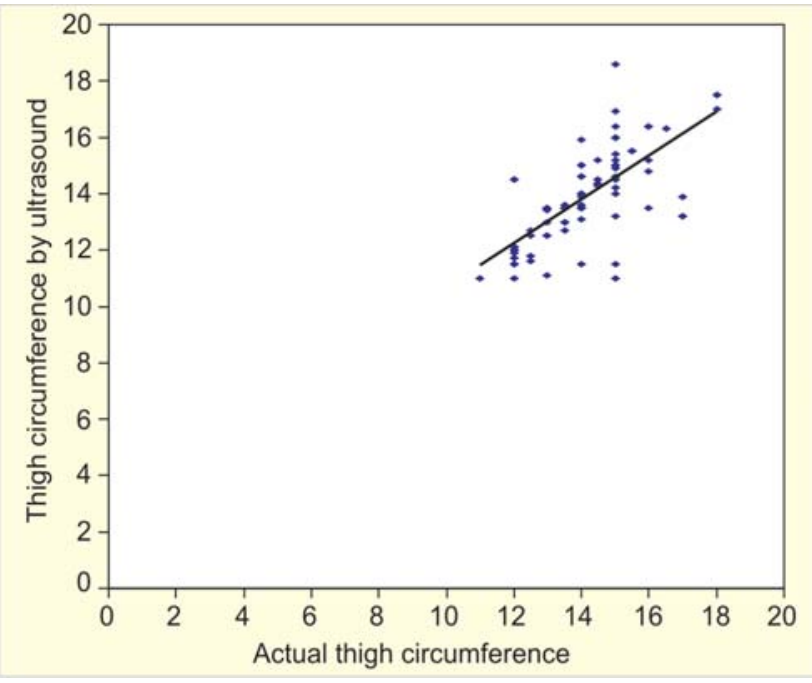

Fig. 3: Scatter diagram showing correlation between actual thigh circumference with thigh circumference on ultrasound

\begin{tabular}{llllllll}
\hline \multicolumn{7}{c}{ Table 1: Comparison of fetal weight estimation formulae } \\
\hline Method & $r^{2}$ & Mean $(g)$ & $\begin{array}{l}\text { Mean } \\
\text { residual }(g)\end{array}$ & $\begin{array}{l}\text { Mean } \\
\text { absolute } \\
\text { error }(g)\end{array}$ & $\begin{array}{l}\text { Mean } \\
\text { absolute } \\
\text { percentage } \\
\text { error (\%) }\end{array}$ & $\begin{array}{l}\text { Mean } \\
\text { deviation } \\
\text { (\%) }\end{array}$ & $\begin{array}{l}\text { Ability to } \\
\text { predict } \\
\text { within 10\%(\%) }\end{array}$ \\
\hline Johnson's & 0.7393 & 3420 & 557 & 563 & 20.7 & 20.5 & 22 \\
Hadlock's & 0.8722 & 2701 & -162 & 237 & 8.3 & -5.4 & 67 \\
Vintzileos' & 0.9543 & 2721 & -142 & 167 & 5.8 & -4.9 & 89 \\
\hline
\end{tabular}




\section{DISCUSSION}

Over the years, the science of fetal weight prediction has evolved from simple palpation to ultrasonographic measurements of various parameters of the fetus, and development of objective regression equations. But till date, the models used to predict fetal weight are not very accurate, and there is always a scope for the better and more accurate method.

Various regression equations are available based on fetal parameters like abdominal circumference, head circumference, femur length and biparietal diameter. The most commonly used equations are based on abdominal circumference, biparietal diameter and femur length. ${ }^{5-8}$ Vintzileos et al devised another equation, and incorporated thigh circumference, in addition to abdominal circumference, biparietal diameter and femur length. ${ }^{9-11}$

Several authors have shown the unacceptable level of intraand interobserver variability in fetal measurement, and the impact of errors on growth assessment

In the present study, using Vintzileos' method viz. incorporating thigh circumference measurements along with biparietal diameter, abdominal circumference and femur length measurements, gave the coefficient of correlation as 0.9543 , mean absolute error of $167 \mathrm{gm}$, and mean absolute percentage error of $5.8 \%$. This method was able to predict $89 \%$ of the birth weights, within $\pm 10 \%$ of actual birth weight. Mean residual in different weight categories were $\pm 108, \pm 138, \pm 175$ and \pm 184 respectively. The sensitivity of this method in predicting birth weights $<2500$ gm was $88.4 \%$, specificity was $94.3 \%$, positive predictive value was $85 \%$ and negative predictive value was $96 \%$, and the corresponding values were $69 \%, 86 \%, 64 \%$ and $88.8 \%$ by Hadlock's method. In babies > 2500 gm, sensitivity, specificity, positive predictive value and negative predictive value by Vintzileos’ method were 85\%, 73\%, 90\% and $63 \%$ respectively. The corresponding values were $93 \%$, 92\%, 97\% and 83\% respectively by Hadlock's method.

The results of the present study are comparable with the original study by Vintzileos et al, and it has proved better than the Hadlock's method in accurately predicting fetal weight. ${ }^{9}$

In a study by Lee et al, fractional thigh volume $(r=0.86)$, fractional upper arm volume $(r=0.83)$, abdominal circumference $(r=0.83)$, and mid-thigh circumference $(r=0.82)$ were highly correlated with birth weight. It correctly predicted 20 of 30 birth weights to be within $5 \%$ of actual weight. By comparison, the Hadlock's model predicted only 6 of 30 birth weights to be within $5 \%$ of actual weight. ${ }^{12}$

Song et al concluded that thigh volume measurement by three-dimensional ultrasound was simple, and there was better accuracy with this method for predicting fetal weight during the third trimester of pregnancy. ${ }^{13}$ The results of this study indicate that fetal thigh circumference measurements can add further to the accuracy of birth weight estimation in obstetric practice, especially in babies of $<2.5 \mathrm{~kg}$ with $88.5 \%$ predictability. Measurements of thigh circumference provide a potentially straightforward method for assessing the deposition of muscle and fat in the growing fetus. This parameter is preferred over diameter measurements as it is less sensitive to changes in shape.

Pediatric experiences have shown that the thigh circumference is one of the parameters that reflect soft tissue mass. ${ }^{14}$ Formulae incorporating thigh circumference measurements may prove most useful in predicting fetal weight when growth abnormalities are present. Fetal growth aberrations, such as intrauterine growth restriction, are associated with changes in the soft tissue mass, which is decreased in these cases. Recently, imaging fetal limb volume by 3D ultrasound has proved that fetal thigh measurements facilitate accurate prediction of birth weight. However, not all centers are equipped with 3D ultrasound machines and there are some limitations associated with 3D imaging techniques, in optimal visualization of the surface anatomical structures, especially in cases of fetal malpresentations and malpositions. ${ }^{15}$

In a recent study, it is concluded that birth weight estimated through formulae using the fetal arm and thigh volumes assessed through 3D are more accurate than two-dimensional formulae. ${ }^{16}$

The accuracy of EFW is compromised by large intra- and interobserver variability. Efforts must be made to minimize this variability, if EFW is to be clinically useful. This may be achieved through averaging of multiple measurements, improvements in image quality, uniform calibration of equipment, careful design and refinement of measurement methods, acknowledgment that there is a long learning curve, and regular audit of measurement quality. Further work to improve the universal validity and accuracy of fetal weight estimation formulae is required.

\section{CONCLUSION}

The results of this study showed that addition of fetal thigh circumference improves the accuracy of fetal weight prediction. In the present study, Vintzileos' method was found better in the most aspects of accuracy in the subcategories based on birth weight except $>3500$ gm where it was found comparable to Johnson's and Hadlock's method, which could have been because of a small sample size.

\section{REFERENCES}

1. Hanretty KP, Neilson JP, Fleming EE. Re-evaluation of clinical estimation of fetal weight: A comparison with ultrasound. J Obstet Gynecol 1990;10:199-201.

2. Chauhan SP, Sullivan CA, Lutton TC, Magann EF, Morrison JC. Parous patients' estimate of birth weight in post term pregnancy. J Perinatol 1995;15:192-94.

3. Bossak WS, Spellacy WN. Accuracy of estimating fetal weight by abdominal palpation. J Reprod Med 1972;9:58-60.

4. Hadlock FP, Harrist RB, Carpenter RJ, Deter RL, Park SK. Sonographic estimation of fetal weight. The value of femur length in addition to head and abdomen measurements. Radiology 1984;150:535-40. 
5. Hadlock FP, Harrist RB, Sharman RS, Deter RL, Park SK. Estimation of fetal weight with the use of head, body, and femur measurements: A prospective study. Am J Obstet Gynecol 1985;151:333-37.

6. Vintzileos AM, Campbell WA, Rodis JF, Bors KR, Nochimson DJ. Fetal weight estimation formulas with head, abdominal, femur, and thigh circumference measurements. Am J Obstet Gynecol 1987;157:410-14.

7. Johnson RW, Toshach CE. Estimation of fetal weight using longitudinal menstruation. Am J Obstet Gynecol 1954;68:891.

8. Vintzileos AM, Neckles S, Campbell WA. Ultrasound fetal thigh-calf circumferences and gestational age-independent fetal ratios in normal pregnancy. J Ultrasound Med 1985:4:287.

9. Lee W, Deter RL, Ebersole JD, Huang R, Blanckaert K, Romero R. Birth weight prediction by three dimensional ultrasonography: Fractional limb volume. J Ultrasound Med 2001;20:1283-92.

10. Song TB, Moore TR, Lee JI, Kim YH, Kim EK. Fetal weight prediction by thigh volume measurement with three-dimensional ultrasonography. Obstet Gynecol 2002;96:157-61.
11. Mohan M, Ramji S, Satyanarayana L, Marwah J, Kapani V. Thigh Circumference in assessing malnutrition in preschool children. Indian Pediatrics 1988;25:255-57.

12. Zeitlin MF. Comparison of malnourished children selected by weight-for-age, mid-upper-arm circumference, and maximum thigh circumference. J Trop Pediatrics 1986;32:190-95.

13. Nardozza LM, Vieira MF, Araujo Júnior E, Rolo LC, Moron AF. Prediction of birth weight using fetal thigh and upper arm volumes by three dimensional ultrasonography in a Brazilian population. J Matern Fetal Neonatal Med 2010 May;23(5): 393-98.

14. Dudley NJ.A systematic review of the ultrasound estimation of fetal weight. Ultrasound Obstet Gynecol. 2005 Jan;25(1): 80-89.

15. Chang FM, Liang RI, Ko HC, Yao BL, Chang $\mathrm{CH}$, Yu CH. Three-dimensional ultrasound-assessed fetal thigh volumetry in predicting birth weight. Obstet Gynecol 1997;90(3):331-39.

16. Nardozza LM, Araújo Junior E, Vieira MF, Rolo LC, Moron AF. Estimate of birth weight using two- and three-dimensional ultrasonography. Rev Assoc Med Bras 2010;56(2):204-08. 